\title{
O PROCESSO DE CONSTRUÇÃO DA UNESP CORPORATIVA
}

\author{
José Luís BIZELLI ${ }^{1}$ \\ Maíra da Cunha DARIDO ${ }^{2}$
}

RESUMO: O artigo apresenta o Programa de Educação Corporativa da Universidade Estadual Paulista - UNESPCorp -, cujo objetivo é desenvolver o quadro de pessoal da instituição rumo ao seu aprimoramento profissional, utilizando tecnologias de educação à distância $(\mathrm{EaD})$. O projeto piloto da UNESPCorp foi iniciado com o curso de Aperfeiçoamento em Licitação e Contratação Pública. O curso foi realizado no segundo semestre de 2012 e recebeu 130 servidores representando todos os campi da UNESP. O texto está dividido em duas partes, sendo que a primeira recupera o contexto histórico no qual se insere a Universidade Corporativa. A segunda parte apresenta os desafios e avanços representados pela primeira versão do curso, assim como sua estrutura pedagógica de funcionamento.

PALAVRAS-CHAVE: Educação à distância. Universidade corporativa. Educação continuada para o trabalho.

\section{Introdução}

O ritmo com o qual as inovações tecnológicas vêm ganhando espaço na sociedade moderna provoca uma intensa necessidade do ser humano educar-se para as mediações que se constroem entre os conteúdos que desenham as profissões e o ambiente vivido pelas organizações modernas. Novas habilidades, novos significados e constantes rupturas no campo dos valores éticos que conformam o mundo do trabalho desenham a estrutura que rege as organizações, particularmente aquelas que estão voltadas ao setor público estatal.

O uso da comunicação e da mídia criaram novas formas de ação e interação com o mundo, novas relações sociais, diferentes olhares sobre os outros e sobre si mesmo (HALL, 2001). As relações que antes eram face-a-face fluem por plataformas midiáticas, as quais possibilitam a comunicação e a troca de informações, em tempo real, com pessoas que estão em outros lugares, rompendo a ideia de fronteiras e relativisando a noção de distância (CASTELLS, 2010).

1 UNESP - Universidade Estadual Paulista. Faculdade de Ciências e Letras - Departamento de Antropologia, Política e Filosofia. Araraquara - SP - Brasil.14800-901 - bizelli@fclar.unesp.br

${ }^{2}$ Mestranda em Educação Escolar. UNESP - Universidade Estadual Paulista. Faculdade de Ciências e Letras - Pós-Graduação em Educação Escolar. Araraquara - SP - Brasil. 14800-901 maira_darido@yahoo.com.br 
A globalização massificou as culturas e a internacionalização dos dispositivos que têm embarcado em seus microchips as tecnologias de comunicação e informação (TIC) - destruiu os sentidos do espaço e do tempo, colocando sob suspeita o encantamento da descoberta sobre o desconhecido, que hoje só é possível na ficção (BIZELLI; SANTOS, 2011) já que todas as experiências da materialidade se encontram nos sites de busca da rede mundial de computadores.

As TIC trouxeram a notícia e a escolha do ângulo de análise para mais perto do internauta, a pluralidade de leituras disponíveis fortalecem os atores sociais e sua capacidade de decisão. Diminuem-se fronteiras entre os espaços materiais concretos e a vida dos seres humanos. Com as inovações tecnológicas e maior rapidez na circulação da informação, a educação precisa extrapolar o campo espacial e atingir outras distâncias para além das barreiras físicas. Assim, segundo Kenski (2003), a educação à distância $(\mathrm{EaD})$ coloca-se como ferramenta de fundamental importância para a nova noção do tempo no processo de aprendizagem.

$\mathrm{Na}$ lógica do mercado a alta competitividade e a necessidade de sobrevivência das grandes corporações apontam para a formação continuada de servidores, sendo necessário aperfeiçoar e buscar ferramentas que auxiliem o constante estudo e atualização dos funcionários (EBOLI, 2004).

O contexto esboçado mostra a importância de se pensar, criticamente, o papel estratégico das universidades corporativas no Brasil. Segundo Pacheco (2002), as universidades corporativas buscam transmitir os valores da empresa para os funcionários além de oferecer a eles ferramentas e novas habilidades para o crescimento profissional e conteúdos que os auxiliem a superar os desafios cotidianos colocados pelo ambiente de trabalho.

Assim, é fundamental entender qual o papel de uma universidade corporativa dentro do setor público, no segmento que atua, particularmente, na área da Educação e mais especificamente na Educação Superior. O trajeto feito aqui, portanto, parte da contextualização sobre o ambiente que envolve a UNESPCorp para chegar à análise de uma primeira experiência realizada através da implantação do Aperfeiçoamento em Licitação e Contratação Pública, no segundo semestre de 2012.

\section{Novas configurações sociais: das novas demandas do mercado à educação corporativa}


O processo de globalização, o avanço acelerado das inovações tecnológicas, a velocidade das mudanças, a complexidade crescente do viver em sociedade e as incertezas quanto ao futuro (BAUMAN, 2001; CANCLINI, 2007) estão exigindo das organizações transformações cada vez mais rápidas e profundas para que se mantenham competitivas tanto no âmbito nacional quanto internacional.

É nesse cenário que emergem, no século XX, novas necessidades em todos os campos da vida moderna, especialmente no campo do trabalho. Tornou-se cada vez mais necessário o aperfeiçoamento dos produtos colocados à disposição do cidadão e a especialização do capital humano que articulam as tarefas das organizações (EBOLI, 2004).

O cuidado com o atendimento às expectativas do cliente - no caso do setor público do cidadão - passou a ser imprescindível para o bom desenvolvimento e fortalecimento das empresas ou organizações, já que elas foram incitadas a adaptar-se às transformações tecnológicas vigentes, assim como a atualizar continuamente seus funcionários em função das novas ferramentas e habilidades de trabalho que emergem e modificam a estruturação dos processos organizacionais.

Segundo Amaral (2003), porém, na "nova economia" da Era do Conhecimento, não basta investir no acesso às novas tecnologias e em sistemas de informação e comunicação avançada, é primordial contar com uma base de conhecimentos sustentada por um processo de aprendizado contínuo, considerado não apenas como instrumento de competitividade, mas também como aprendizado social, possibilitando aos indivíduos a prerrogativa de se valerem das mudanças técnicas em prol do pleno exercício de sua cidadania (MACK, 2008).

Assim, por um lado, as organizações passaram a investir grandes somas de recursos em inovações tecnológicas que incrementam positivamente os procedimentos operacionais existentes e, por outro lado, passaram a educar seus funcionários para o trabalho. O capital intelectual é, hoje, um fator competitivo fundamental. A contribuição que o funcionário coloca a serviço da organização, através de seus conhecimentos, faz toda a diferença para a avaliação dos resultados atingidos pelas instituições, sejam elas privadas, públicas ou do terceiro setor.

Ganha força, portanto, a educação continuada para o trabalho e o incentivo das corporações em apoiar o aperfeiçoamento/qualificação - formal - de seus funcionários. (DE LUCA, 2006) 
No âmbito da administração pública, os projetos de educação continuada passaram a adotar o modelo de "escolas de governo", ou de "escolas corporativas de gestão do governo" que constituem, na atualidade, a principal estratégia para atender às expectativas e necessidades crescentes dos cidadãos e assegurar o alto desempenho das organizações que atuam na esfera de governo ou no setor público não estatal. (AMARAL, 2003).

O foco das iniciativas das "escolas" citadas está construído sobre o conhecimento relativo à área de atuação da organização. $\mathrm{O}$ modelo de universidade corporativa como estratégia de produção, retenção e disseminação do conhecimento, pode ser analisado como parte das estratégias de aprofundar-se no se produz dentro da organização (EBOLI, 2004).

O objetivo é a introdução de um processo contínuo de aprendizagem, direcionado para oferecer aos funcionários, fornecedores, clientes e à comunidade, os conhecimentos, as qualificações e as competências necessárias para atingir as metas estratégicas do setor a que servem. Não é por coincidência que o setor público é um dos mais interessados em implantar universidades corporativas (MEISTER, 1999).

Enquanto antes, o foco do trabalho e da produtividade estava sustentado pelo aparato técnico, na Era do Conhecimento o interesse tem como foco as pessoas e a necessidade de desenvolvimento de competências relacionadas à liderança, a criatividade, a pró-atividade, a ética e a cidadania, ao relacionamento interpessoal, dentre tantas outras.

Sendo assim, um projeto de aprendizagem corporativa não deve somente prestar atenção em programas de desenvolvimento técnico, atendendo a certas necessidades pontuais da organização, mas sim, deve desenvolver o capital intelectual que ali trabalha, através de ações educacionais que estimulem a pensar, a liderar, a se relacionar, a criar e a construir coletivamente (AMARAL, 2003).

Para tanto, a organização precisa criar mecanismos educacionais que possibilitem o aperfeiçoamento constante do funcionário/estudante para que ele, além de se desenvolver tecnicamente, promova a cultura da instituição para seus colaboradores. Tão importante quanto - num contexto de aprendizagem coletiva -, criam-se condições para que haja a transformação do conhecimento tácito dos integrantes da equipe em conhecimento explícito para a equipe. $O$ foco é no aprendizado organizacional, e não no aprendizado individual. É essencial que os líderes 
e gestores participem ativamente do processo de aprendizagem coletiva, como lideranças educadoras e motivadoras do desenvolvimento da equipe.

A busca pela excelência permeia o cenário tanto privado, quanto público. Notase o crescimento, ainda que pequeno, das iniciativas voltadas à educação corporativa nas educações governamentais. Segundo Pacheco (2002), as escolas de governo são mais eficazes quando se constituem como "escolas corporativas de gestão do governo", já que desenvolvem melhor produtos e serviços que agregam valor imediato ao desempenho da administração pública. Alinhadas à agenda de governo para a gestão pública, caminham de forma semelhante às universidades corporativas, desenvolvidas por grandes empresas privadas para assegurar o alinhamento da educação funcional oferecida com os valores e desafios estratégicos postos pela Sociedade do Conhecimento (MACK, 2008).

Eboli (2004) também definiu como um dos princípios no qual as universidades corporativas devem se pautar a sua disponibilidade: as experiências mais bemsucedidas, segundo a autora, fundamentam-se na educação à distância $(\mathrm{EaD})$ e no uso intensivo de tecnologia, em suas mais diversas formas, para criar um ambiente organizacional propício à aprendizagem ativa, contínua e compartilhada.

As universidades corporativas no Brasil são relativamente recentes (MEISTER, 2009), surgiram a partir da década de 90 e aos poucos foram substituindo os departamentos de P\&D (Pesquisa e Desenvolvimento) muito usual na maioria das grandes corporações. A educação corporativa surge em um novo contexto social onde a educação é voltada para o crescimento individual e coletivo do trabalhador acarretando um maior desenvolvimento da organização como um todo.

Para que sejam desenvolvidas as novas habilidades para o exercício do mundo do trabalho, há que se conceber um novo padrão para o processo de aprender e ensinar. Torna-se preciso rever a interpretação da educação profissional.

Em verdade, todos os campos da vida social podem ser concebidos como unidades de aprendizagem para a vida cidadã, assim como, a organização laboral deve tornar-se uma learning organization. A rapidez com a qual se processa o conhecimento exige que as instituições mesclem o aprendizado vivencial do dia-a-dia com o aprendizado tradicional, formal.

Para Dowbor (2008), toda pessoa precisa periodicamente voltar a estudar, sob pena de ver-se marginalizada no universo do trabalho, sob pena de não saber utilizar o novo equipamento que foi projetado para responder demandas do seu setor ou para 
acompanhar as novas demandas do mercado de consumo. Ainda ressaltando a importância de absorção de inovações no universo da corporação:

Educação Corporativa é um guarda-chuva estratégico para desenvolver e educar funcionários, clientes, fornecedores e comunidade, a fim de cumprir as estratégias empresariais da organização. (MEISTER, 1999, p.29).

Como objetivos específicos, a educação corporativa busca desenvolver nas pessoas competências profissionais, técnicas e gerenciais, ou seja, as competências humanas necessárias para a viabilização das estratégias da organização. Portanto, é fundamental que a empresa identifique qual ou quais são suas competências essenciais, aquelas que realmente se constituirão em diferencial competitivo no mercado de circulação de produtos.

A inserção das TIC no cotidiano das práticas de ensino para o mundo profissional fomenta a discussão sobre o desenvolvimento cognitivo através das competências que elas permitem. Vem à tona um novo modelo de educação e aperfeiçoamento difundido através das experiências de EaD (KENSKI, 2003).

EaD é uma estratégia que chama a atenção pela possibilidade de constante aprimoramento e possibilidades oferecidas ao educando. Definitivamente, a modalidade ganha espaço no contexto organizacional e na educação corporativa, fazendo com que se concretize a meta de transformar o investimento aplicado no desenvolvimento de pessoas em elemento básico para o sucesso da organização.

Por suas características de flexibilidade e interatividade, a $\mathrm{EaD}$ atende com maior velocidade a construção de conhecimentos dentro dos ambientes organizacionais. Ela possibilita a melhoria da qualidade dos profissionais colaboradores com rapidez e agilidade, contribuindo diretamente com a redução de custos com educação continuada para o trabalho, maior alcance territorial do público alvo e melhoria na gestão dos recursos humanos envolvidos com o projeto.

$\mathrm{O}$ ambiente da internet oferece uma atualização de conhecimento rápida, principalmente sobre produtos e serviços desenvolvidos pela organização (PACHECO, 2002). As novas plataformas digitais permitem processos integrativos que colocam à disposição dos educandos conhecimentos que organizam uma forma nova de aprender através do pensar digital, ou seja, um pensar sem intermediações. 
As universidades corporativas surgem, portanto, para o preenchimento de uma lacuna entre funcionários que necessitam de maiores conhecimentos e a instituição constantemente forçada a inovar em seus procedimentos, dinâmicas - internas ou externas - e produtos para o mercado. Mais do que isso, quando a instituição se encaminha para o modelo learning organization se criam condições para um cenário educacional que equaliza valores, padroniza procedimentos e agrega conhecimentos em tudo que faz.

O ensino se democratiza, de forma que a sala de aula ou os ambientes virtuais de aprendizagem (AVA) transformam-se em espaço de troca de experiências de vida na organização e as teorias das diferentes áreas do conhecimento ganham concretude na orientação de condutas profissionais.

As próprias pessoas passam a promover seu desenvolvimento para o trabalho e, como profissionais, ganham autonomia frente ao seu processo de aprendizagem. Por um lado, desenvolve-se a tecnicidade e as habilidades laborais, enquanto, por outro lado, adquirem-se as competências da vida cidadã, já que todos se transformam em atores promotores de maior qualidade de vida para si e para os outros.

A era da Educação, pós-revolução industrial, reflete a lógica do constante movimento, exaltando a necessidade de um tipo de conhecimento diferente dos cursos acadêmicos tradicionais, um conhecimento holístico, não fragmentado como acontece nos cursos que formam um tipo de profissional especifico. A educação corporativa pode ser considerada, assim, um novo segmento do cenário educacional. Segundo Amaral (2003), ela vem ganhando espaço estratégico nas organizações e por isso, deve ser encarada como mais um nível do processo educacional das pessoas, complementando o nível médio e superior.

A implantação de uma Universidade Corporativa exige um programa educacional que trabalhe na missão e na visão de futuro da instituição. $\mathrm{Na}$ presente investigação, como a instituição é a Universidade Estadual Paulista "Júlio de Mesquita Filho" - a UNESP -, cujos objetivos estratégicos estão ligados a plenos de ação para colocar à disposição da sociedade conhecimento, ciência, pesquisa e inovação, formando profissionais aptos para atender as demandas dos cidadãos brasileiros, a educação corporativa não se fundamenta simplesmente na formação para o trabalho.

O princípio fundamental da UNESPCorp, objeto de análise deste texto, não se limita em melhorar o desempenho dos funcionários e da instituição, mas oferecer aos servidores a possibilidade de uma formação continuada e de qualidade para a vida. 


\section{A educação corporativa na UNESP}

A ideia de uma Universidade Corporativa com a marca da UNESP agrega a experiência em educação continuada para o trabalho com a possibilidade de seus quadros funcionais progredirem por meio da educação formal, ou seja, da graduação e da pós-graduação - lato sensu ou stricto sensu profissionalizante. Sendo uma Unidade Universitária do sistema estadual de ensino superior paulista - público, gratuito e de qualidade -, já responde por uma série de cursos de graduação e pós-graduação, ajudando a preparar profissionais para o mundo do trabalho.

Assim, nada mais natural do que se voltar para a formação de seu corpo técnico administrativo. Franquear condições de frequência a cursos de graduação para aqueles que não tiveram a oportunidade de fazê-los, de pós-graduação para os que já têm a graduação e cursos de especialização e de aperfeiçoamento para os demais trabalhadores universitários.

Formar recursos humanos para uma Universidade de Excelência é desafio a ser vencido pela instituição que está comprometida com serviços de qualidade para os cidadãos que vêm estudar no estado de São Paulo. A UNESPCorp não inviabiliza ações pontuais importantes venham a ser feitas - e deverão continuar a serem feitas - em formação continuada, através de cursos que abordem o cotidiano do serviço técnicoadministrativo. A UNESP deve, estrategicamente, criar as oportunidades de educação formal para seus quadros funcionais.

Em verdade, há um interesse expresso, recorrentemente, entre os servidores técnico-administrativos no sentido de que haja investimentos na formação de quadros preparados para enfrentar os desafios cotidianos do trabalho. Outro indicador que pode medir a adesão do quadro funcional a programas de educação formal é o que vem do programa de bolsas oferecidas pela Reitoria para aqueles que querem investir em sua graduação. A UNESP investe no programa de bolsas, as quais financiam cursos de graduação em outras Unidades Universitárias que nem sempre têm a qualidade do sistema de ensino superior público do estado de São Paulo.

Uma grande universidade pública não tem porque entregar a formação de seus quadros para o mercado: ela tem condições de oferecer a qualidade de ensino que a comunidade interna deseja. Por ser assim, ganhou força na administração da UNESP, no ano de 2012, a ideia de implantar um embrião estratégico do que pode vir a estar 
reunido em uma Universidade Corporativa - a UNESPCORP - totalmente voltada para a educação formal dos servidores técnico-administrativos.

A UNESPCORP permite que o candidato a um posto de trabalho na UNESP vislumbre a possibilidade de ascender na carreira através de um projeto de ensino com a marca da instituição. Aqueles que não possuem a graduação poderão fazê-la; aqueles que já forem graduados terão oportunidade de ingressarem em programas de pósgraduação lato ou stricto sensu e aqueles que necessitarem de cursos de aprimoramento para melhor desempenhar suas funções, também terão um conjunto de cursos à disposição. As vantagens para a instituição são imensas.

Primeiro, uma Universidade que estabeleceu em seu PDI - Plano de Desenvolvimento Institucional - os valores que a regem, tem no ensino corporativo um instrumento para, permanentemente, difundi-los e rediscuti-los com seus servidores técnico-administrativos.

Segundo, a sala de aula da Universidade corporativa é o local adequado de discussão sobre os Procedimentos Operacionais Padrão (POP) para todas as áreas, diminuindo concretamente as distâncias entre as várias Unidades e também a distância destas com a Reitoria.

Terceiro, os materiais produzidos pela Universidade corporativa e os cursos de aprimoramento contínuo - numa época em que o trabalhador é cada vez menos estável no posto de trabalho, ou seja, em um momento no qual o turn over é muito alto - é a garantia de diminuição do tempo de treinamento especializado e uma forma de confiança na formação para os que ingressam na carreira técnico-administrativa unespiana.

Quarto, os professores que ministram cursos podem construir um laboratório de experiências que vai permitir à UNESP refletir sobre suas práticas administrativas, aprimorando sua ciência de administrar o bem público diante tanto dos valores organizacionais da instituição quanto do compromisso ético com o serviço público e com a formulação de estratégias e práticas que diminuam a distância entre $o$ compromisso ético e o serviço prestado no último guichê de atendimento da Unidade mais distante.

Quinto, como a UNESPCORP deve ter uma grande parte de suas atividades baseadas em EaD, é possível que esteja disponível para os servidores um conjunto de cursos na ponta dos dedos, permitindo a consolidação dessa metodologia na UNESP e facilitando a vida dos funcionários que querem progredir na vida e na carreira. Aqui é 
importante lembrar que a instituição, através do NEAD - Núcleo de Educação a Distância -, foi a primeira, no Brasil, a implantar a Universidade Aberta, cujo intuito é disponibilizar, gratuitamente, os conteúdos e materiais didáticos dos cursos de graduação, pós-graduação e extensão da Universidade para qualquer pessoa com acesso a Internet, no modelo conhecido como MOOC - Massive Open Online Course.

O modelo de Universidades corporativas tem obtido resultados interessantes em várias instituições, constituindo-se como centros de excelência para formar servidores. Exemplos bem sucedidos podem ser citados em organizações como a Petrobrás, a Eletrobrás, o Sebrae e a Caixa Econômica Federal. A UNESPCorp cria um espaço estratégico para a formação de recursos humanos que Universidade almeja.

\section{O curso de aperfeiçoamento em contratação e licitação pública}

O piloto do projeto da UNESPCorp foi o Curso de Aperfeiçoamento em Licitação e Contratação Pública, realizado na modalidade semipresencial, cujo início se deu em agosto de 2012 e o término em dezembro do mesmo ano. Com 130 vagas, o curso foi destinado aos Diretores Técnico-administrativos e aos servidores responsáveis pelas áreas de Materiais e Compras e de Contabilidade e Finanças das Unidades Universitárias da UNESP.

A metodologia foi reunir servidores dos 34 campi e da Reitoria da Instituição para, primeiro, discutirem suas práticas administrativas - inclusive aquelas que envolvem as questões vinculadas à temática de contratações e licitações públicas -, depois descreverem seus procedimentos operativos e, por fim, consolidarem em uma cartilha as conclusões sobre as formas mais efetivas de enfrentamento dos desafios do trabalho que realizam.

Os objetivos explícitos no PDI da Unesp - emoldurados por sua missão ${ }^{3}$ e sua missão ${ }^{4}$ - não podem ser cumpridos apenas pelo trabalho de Ensino, Pesquisa, Extensão e Gestão dos servidores docentes; a excelência não pode ser medida apenas pelas

\footnotetext{
${ }^{3}$ Exercer sua função social por meio do ensino, da pesquisa e da extensão universitária, com espírito crítico e livre, orientados por princípios éticos e humanísticos. Promover a formação profissional compromissada com a qualidade de vida, a inovação tecnológica, a sociedade sustentável, a equidade social, os direitos humanos e a participação democrática. Gerar, difundir e fomentar o conhecimento, contribuindo para a superação de desigualdades e para o exercício pleno da cidadania.

${ }^{4}$ Ser referência nacional e internacional de Universidade Pública multicâmpus, de excelência no ensino, na pesquisa e na extensão universitária, que forme profissionais e pesquisadores capazes de promover a democracia, a cidadania, os direitos humanos, a justiça social e a ética ambiental, e que contribua para o letramento científico da sociedade e para a utilização pública da ciência.
} 
avaliações do mercado de trabalho ou da participação na vida acadêmica nacional, através da competência dos profissionais que se formam na Instituição.

O reconhecimento da qualidade do serviço prestado ao cidadão-educando tem uma de suas faces fundamentais na qualidade dos quadros de servidores técnicoadministrativos. O desafio é dar inicio a um processo de aprimoramento contínuo que permita e incentive os servidores a reconstruir de forma participativa o fazer administrativo dentro da Unesp.

Assim, o curso caminhou por duas vertentes. Enfocou, por um lado, questões da aprendizagem organizacional, cujo resultado foi o desenvolvimento da cartilha, e, por outro lado, criou um ambiente de aprendizagem para que os cursistas construíssem e/ou aprimorassem seus conhecimentos sobre processo licitatório, sob a ótica da doutrina especializada e da análise da interpretação realizada pelos Tribunais Superiores e de Contas.

Sua apresentação se deu em módulos. Cada módulo de conteúdos continha três pacotes de informação - enviados um a cada semana -, um pacote de reposição ou esclarecimento de dúvidas, todos ministrados na forma EaD. O fechamento do módulo foi feito de forma presencial, na quinta semana.

O encontro presencial teve dois momentos: pela manhã, havia uma abordagem de gestão do dia-dia; pela tarde, oficinas para formalização de procedimento padronizado de enfrentamento de desafios do setor ao qual o servidor técnicoadministrativo pertencia. Em cada fase foram disponibilizados materiais de acompanhamento e de orientação. O conteúdo foi disponibilizado com material produzido pela equipe do NEAD e pela TV UNESP. No final do curso todo material foi consolidado nas cartilhas de procedimentos operacionais padrão e os conteúdos das disciplinas em forma de livro.

A programação do curso incluiu aspectos relacionados ao controle interno e externo na administração pública - tendo em vista a necessidade de formação de uma gestão pública eficiente, aspecto que constitui instrumento essencial para assegurar eficácia e economicidade na Administração e na aplicação dos recursos públicos -; aos instrumentos para evitar desvios, perdas e desperdícios; às rotinas administrativas para garantir o cumprimento das normas técnicas e legais; aos procedimentos para identificar falhas e fraudes; às medidas para preservar o patrimônio público; às ações para levantar informações gerenciais facilitando os processos de tomada de decisões estratégicas, dando visibilidade às atitudes tomadas pela Instituição. 
Os processos licitatórios, por sua vez, foram tratados de forma a familiarizar os servidores com os novos institutos e a jurisprudência recente sobre a questão, tornando acessível todas as modalidades de procedimentos licitatórios. A preocupação foi indicar medidas eficazes para cada fase, visando à legalidade e à efetivação dos demais princípios que norteiam a Administração Pública.

Quanto aos contratos, a Autarquia Pública, ao celebrá-los para atender a realização de compras e obras, deve ter servidores capacitados que utilizem as modernas técnicas de gerenciamento e fiscalização, a fim de, não só atingir máxima otimização na efetivação contratual, mas também, a justa e correta homenagem aos princípios informadores e norteadores da Administração Pública. Os princípios que regem a Gestão de Contratos no setor público puderam ser debatidos e absorvidos pelos servidores.

Com a finalidade de discutir a terceirização de mão de obra na administração pública, o curso transitou pelo caminho, hoje existente, de transferência de atividades para fornecedores especializados. Detentores de tecnologia própria e moderna, atuando no setor terceirizado como sua atividade-fim, as empresas liberam a tomadora de serviços para concentrar seus esforços gerenciais em seu negócio principal - no caso da UNESP oferecer educação superior pública, gratuita e da qualidade -, enquanto se preserva e se melhora a qualidade e produtividade do atendimento, reduzindo custos e ganhando competitividade.

Aspectos relacionados aos tributos, recolhimentos e responsabilidades foram tratados de forma a aproximar os cursistas das principais hipóteses de incidência tributárias as quais o ordenamento nacional permite a retenção na fonte. Para tanto, contou-se, ainda, com o estudo pormenorizado das circunstâncias que geram as retenções na fonte em ISSQN, IR e em sede de INSS, bem como das normas legais e cálculos corretos para este recolhimento.

Todos esses assuntos foram trabalhados de forma a favorecer a atuação dos servidores e para construir uma visão mais completa possível que foi formalizada na cartilha.

As atividades semanais foram realizadas no Ambiente Virtual de Aprendizagem (AVA). O curso adotou com plataforma o MOODLE. Os cursistas foram divididos em três diferentes salas - acompanhados por tutores de diferentes expertises. Em alguns momentos as salas eram compostas aleatoriamente, em outros, particularmente quando se focou na elaboração da cartilha de procedimentos de cada setor, foi estratégico 
agrupar os servidores técnico-administrativos de acordo com suas respectivas áreas. Ferramentas como fóruns, chats e elaboração de textos acompanharam todos os momentos das atividades.

Os encontros presenciais aconteceram na cidade de Araraquara, na Faculdade de Ciências e Letras, criando oportunidade para as discussões sobre os conteúdos com os professores responsáveis pelos conteúdos e para as dinâmicas de construção da cartilha. Outro recurso utilizado nos encontros presenciais foi chamar, pela manhã, palestrantes especialistas nas questões tratadas. Todos os encontros presenciais foram registrados e filmados pela equipe de apoio do curso. Todo o material foi disponibilizado ao fim do curso para os participantes.

\section{Considerações finais}

Como é possível verificar por tudo que foi dito até aqui, as Universidades Corporativas - como foi verificado no embrião da UNESPCorp - têm um potencial para educar formalmente os servidores técnico-administrativos de uma Instituição. Inclusive o fato de se estar falando de uma organização muito particular, a Universidade, diminui os riscos apontados por alguns autores (OTRANTO, 2012) quanto à submissão desse tipo de educação aos interesses meramente da corporação empresarial que financia os cursos. O que se reafirma aqui, então, como objeto da investigação proposta, é a tendência que se fortalece na atualidade do surgimento do ensino corporativo na esfera pública (MACK, 2008).

Diante das determinações da legislação, é habitual que a gestão das unidades universitárias recaia, hoje, sobre os servidores docentes, já que eles fazem parte do quadro permanente capaz de orientar - dar a Direção - a organização para cumprir as metas acadêmicas, segundo os valores da Instituição. O usual, no entanto, é que servidores técnico-administrativos ou docentes não estejam aptos a utilizar-se de estratégias para a gestão compartilhada do espaço universitário, por dois motivos: docentes não foram formados - em sua maioria - para administrar e servidores técnicoadministrativos têm pouco tempo para aprender a aprender em questões de gerenciamento da coisa pública.

Embora cursos de lideranças possam dar rudimentos de administração para servidores-docentes, é o quadro da administração profissional e permanente quem deve enquadrar seus líderes nas normas e procedimentos que configuram a Instituição. 
Cumprir essa tarefa, porém, em uma Universidade que não tem uma administração superior e está concretamente distribuída em 34 unidades e mais a Reitoria, não é tarefa fácil.

Sem prover rodadas de discussão entre servidores e sem dar a isso o status de educação formal, como uma universidade corporativa de qualidade, financiando ações dissociadas de um valor estratégico bem definido é fadar a Instituição ao fracasso administrativo.

O caso da UNESPCorp chama atenção por se pautar no princípio da excelência do ensino paulista, logo, o que se quer é oferecer a oportunidade dos servidores adquirirem os valores propostos pela UNESP: ensino de excelência, oportunidade de pesquisa, crescimento através do diálogo e desenvolvimento do senso crítico. Assim, os servidores técnico-administrativos vão se qualificando para enfrentar seus desafios cotidianos no trabalho de forma mais preparada e para uma vida melhor.

Outro aspecto fundamental: o modelo de educação corporativa adotado inclui o $\mathrm{EaD}$, no caso, realizado de forma semipresencial. O EaD por suas características de flexibilidade e interatividade atende com maior velocidade a construção de conhecimentos em organizações, possibilitando o aperfeiçoamento formal dos servidores, contribuindo diretamente com a redução de custos com educação continuada para o trabalho, proporcionando maior alcance territorial e melhoria na gestão dos recursos humanos.

O ambiente da internet oferece, hoje, atualização de conhecimento enquanto transforma o educando em interator ou interagente de seu próprio conhecimento, estimulando o desenvolvimento de novos produtos e serviços.

Segundo Martín Barbero (2006), é importante pensar nos caminhos que a internet percorre até chegar ao conhecimento. Como se dá essa construção até que se provoque o entendimento crítico no receptor. Assim, é necessário contextualizar o processo educacional com a Era da Informação procurando vias que sejam compatíveis com as novas configurações de tempo e do espaço oriundas da modernidade.

A educação corporativa, via EaD, é um novo segmento de educação no cenário das relações ensino-aprendizagem. Ela vem ocupando espaço estratégico nas organizações e por isso, deve ser encarada, por um lado, como mais um nível do processo educacional, complementando o nível médio e o superior; por outro lado, como ensino formal de graduação e pós-graduação. 
Muitos são os desafios e as dificuldades que devem ser compreendidos na busca da excelência do ensino universitário. É um processo em construção que deve anotar acertos e falhas com a finalidade de proporcionar melhores condições de aprendizagem.

\section{THE PROCESS OF CONSTRUCTION OF SÃO PAULO STATE UNIVERSITY CORPORATE EDUCATION PROGRAM - UNESPCOTP}

ABSTRACT: The article presents São Paulo State University Corporate Education Program - UNESPCorp - whose target is to evolve the staff of institution in order of their professional improvement, using distance education technologies (D-learning). The UNESPCorp pilot project started with the Improvement in Bidding and Public Employment curse. The curse was taught on the second semester of 2012 and received 130 employees representing all UNESP campuses. The text was divided in two parts, the first part recovers historical context which introduces the Corporate University. The second part presents challenges and advances represented for the first version of course, even as its pedagogical structure of operation.

KEYWORDS: Distance education. Corporate university. Continuing education for work.

\section{REFERÊNCIAS}

AMARAL, H. O. do Educação corporativa e suas dimensões: estudo exploratório sobre as políticas e práticas em duas empresas brasileiras. 2003. 169f. Dissertação (Mestrado em Administração) - Escola de Administração, Universidade Federal do Rio Grande do Sul, Porto Alegre, 2003.

BAUMAN, Z. Modernidade líquida. Rio de Janeiro: Zahar, 2001.

BIZELLI, J. L.; SANTOS, P. B. O papel dos games na construção de conteúdos midiáticos educativos. Revista Conexão (UCS), v.10, p.101-112, 2011.

CANCLINI, N. G. A globalização imaginada. Tradução de Sérgio Molina. São Paulo: Iluminuras, 2007.

CASTELLS, M. A Sociedade em rede. 6.ed. São Paulo: Paz e Terra, 2010.

DE LUCA, R. Educação a distância: ferramentas sob medida para o ensino corporativo. In: SILVA, M. (Org.). Educação online: teorias, práticas, legislação, formação corporativa. São Paulo: Loyola. 2006. p.475-485.

DOWBOR, L. Democracia econômica: alternativas de gestão social. Petrópolis: Vozes, 2008. 
EBOLI, M. Desenvolvimento e alinhamento dos talentos humanos às estratégias empresariais: o surgimento das Universidades Corporativas. São Paulo: Schmukles Editores, 2004.

HALL, S. A identidade cultural na pós-modernidade. Rio de Janeiro: DP\&A, 2001.

KENSKI, V. M. Tecnologias e ensino presencial e a distância. 2.ed. Campinas: Papirus, 2003.

MACK, B. S. A implantação de uma universidade corporativa no setor público: o estudo de caso da escola de contas e gestão do tribunal de contas do Estado do Rio de Janeiro. 2008. 165f. Dissertação (Mestrado em Administração Pública) - Fundação Getúlio Vargas, Rio de Janeiro, 2008.

MARTÍN-BARBERO, J. Dos meios às mediações: comunicação, cultura e hegemonia. Tradução de Ronald Polito e Sérgio Alcides. 4.ed. Rio de Janeiro: Ed. da UFRJ, 2006.

MEISTER, J. C. Educação corporativa: a gestão do capital intelectual através das universidades corporativas. São Paulo: Makron Books, 1999.

OTRANTO, C. R. Universidades corporativas: o que são e para que servem? Disponível em: <http://www.anped11.uerj.br/30/GT11-2852--Int.pdf >. Acesso em: 10 ago. 2012.

PACHECO, R. S. Escolas de Governo como centros de excelência em gestão pública: a perspectiva da ENAP- Brasil. Revista do Serviço Público, Brasília, v.53, n.1, p.77-90, jan./mar. 2002. 